\title{
Business Practices to Minimize Safety Risks: A Case Study of Two Adventure Tourism Businesses in Malaysia
}

\author{
Noorfaizah Md Zainudin \\ Azman Hashim International Business School, Universiti Teknologi Malaysia \\ Jalan Sultan Yahya Petra 54100, Kuala Lumpur, Malaysia
}

Tel: 60-12-709-5997 E-mail: faizah9.zainudin@gmail.com

\begin{abstract}
Rahayu Tasnim (Corresponding author)
Malaysian-Japan International Institute of Technology (MJIIT)

Universiti Teknologi Malaysia, Jalan Sultan Yahya Petra 54100

Kuala Lumpur, Malaysia

Tel: 60-3-2203-1282Ｅ-mail: rahayutasnim@utm.my
\end{abstract}

Received: December 23, 2019 Accepted: January 19, 2020 Published: February 21, 2020

doi:10.5296/bms.v11i1.16090ＵRL: https://doi.org/10.5296/bms.v11i1.16090

\begin{abstract}
Risk is inherent in adventure tourism. Without risk, adventure tourism will lose their excitement and uniqueness. Managing risk in commercial adventure tourism operation is essential for the safety of travelers. The improper risk management in this business may lead to some issues such as injury and accidents. Risks involved in adventure tourism are frequently highlighted by the media, usually after a reported accident of fatality. The increased in the number of reported accidents by media in the adventure tourism sector recently, may give significant effect and harmful impact on business as well as the whole tourism industry. Thus, it is important for the commercial adventure tourism businesses and company providers to have effective tools and model(s) in managing the risk effectively to avoid any circumstances that lead to accidents in order for the business to run smoothly with high reputation and confidence of customers. This study explores whether or not Malaysian
\end{abstract}


adventure tourism businesses adhere to any risk management guidelines or models. Two preliminary case studies of adventure tourism businesses in Malaysia illustrated that these businesses have no specific guidelines and risk management models that adventure tourism businesses should adhere to. In addition, findings from this study also demonstrated that no specific regulations imposed by the government for adventure tourism businesses to comply to. This study advises on the application and implementation of the Event Management Body of Knowledge (EMBOK) model as part of Malaysian adventure tourism businesses risk management responsibilities.

Keywords: Adventure tourism, Event Management Body of Knowledge (EMBOK), Risk, Risk management, Safety experience

\section{Introduction}

Adventure tourism is one of the fastest expanding niche or segments in the global tourism industry (Clinch et al., 2017; McKay, 2013; Peacock et al., 2017; World Tourism Organization, 2014). According to McKay (2013), adventure tourism is a style of tourism whereby travellers commence a physical activity that would hold as somewhat outside their comfort zone and where some risk to life and extremity is involved. Despite the fact that risk is a main element in the adventure activity, all participants wish to have extraordinary experience without any injuries or accidents (Bentley et al., 2010). Therefore, adventure tourism businesses (operators) play an important role to provide safe and exciting experiences to them. In order to achieve that, risks need to be effectively managed by all commercial operators. Inappropriate risk management by the operator, may lead to loss of firm's reputation, customer confidence, money, employees (Senthilkumaran et al., 2017; Swarbrooke et al., 2003) and worst, loss of entire business (due to close down). Thus, it is important that commercial adventure operator and adventure tourism company provider to have effective tools and model in managing the risk effectively to avoid any circumstances that lead to unfortunate incidents. In addition, this is also crucial to ensure business can be run smoothly with high reputation and importantly to gain confidence from customers. Although risk management in adventure tourism is a concerning issue discussed in global research, in the Malaysian context, this is the opposite. The study related risk management practices by Malaysian adventure tourism businesses has received little research attention. Hence, this study explores whether or not Malaysian adventure tourism businesses adhere to risk management guidelines or models. This study will then seek to advise on the application and implementation of the Event Management Body of Knowledge (EMBOK) model as part of Malaysian adventure tourism businesses risk management responsibilities.

\section{Adventure Tourism Industry Overview}

Adventure tourism segment which combines a variety of activities ranging from high-risk adventure to low ones, could be defined as commercially operated outdoor activities comprising a combination of adventure and excitement experienced in a natural environment (Bentley et al., 2001). Adventure tourism has been prioritized by most countries as a driver to 
economic development because they recognize its ecological, cultural and economic value (World Tourism Organization, 2014). In 2016, this segment was valued at over USD 455 million (Doshi et al., 2018) and has become a major role in the economic growth of most countries in the world with a projected annual growth of over 15\% (Naidoo et al., 2015). Market study on global adventure tourism which conducted by the Adventure Travel Trade Association (ATTA) in 2010 revealed that the global adventure tourism was valued at USD 89 billion. Within two years, the value has a dramatic increase of $195 \%$ and making this segment worth USD 263 billion in 2013 (ATTA, 2013). The increased in the percentage of global adventure tourism value supported the fact that adventure tourism is one of the fastest growing niche or segments in the global tourism industry. Until today, this segment has gained more popularity among today's sophisticated travelers especially for travelers who persistently seek for specific activities with risk, danger or uncertain outcomes such as scuba diving, rock climbing, white water rafting, skydiving and caving to satisfy their desire to engage in adventurous behaviors during their vacation.

\subsection{Adventure Tourism in Malaysia}

According to McKay (2016), physical geography and climate are essential for adventure tourism to flourish. Malaysia is a country that is rich with the natural resources and bestowed with many attractive highlands, beautiful islands, and a variety of rivers (Mapjabil et al., 2017). Thus, Malaysia has a large potential to tap adventure tourism market based on their abundant natural resources which are suitable for adventure sports activities (Isa et al., 2015; Mapjabil et al., 2017). Indeed, this has made Malaysia as an attractive country for travelers from around the world with special interests in adventure sport to experience all kinds of adventure sports activities such as mountain climbing, scuba diving, water rafting, windsurfing, skydiving, jungle trekking as well as other adventure sports (Ibrahim et al., 2016). Due to this advantage, adventure tourism has grown increasingly for more than a decade (Isa et al., 2015) and become a popular segment in Malaysia's tourism industry (Ibrahim et al., 2016; Yusof et al., 2008). Malaysia has acknowledged adventure tourism as a segment that can enhance the country's tourism yield by listing this segment in the twelve initiatives proposed under the tourism National Key Economic Area (NKEA) although this segment considered as a niche market in Malaysia.

\section{Literature Review}

\subsection{Adventure Tourism}

Adventure tourism has significantly created a research momentum in international literature over the last two decades (Peacock et al., 2017). This topic has raised both academics and practitioner's attention as they see the vast potential within this tourism market niche. However, until today, there are no specific definition of adventure tourism exists in the World Travel Organization (UNWTO) and scholar literature. Most scholar agreed that adventure tourism is difficult to define due to its characteristics that overlap with sport, leisure, outdoor recreation and other niche tourism sector such as ecotourism as well as sport tourism (Clinch 
et al., 2017). However, by considering all the elements that comprise in the sport, leisure, adventure and outdoor recreation, Sung et al. (1996) has pointed out that adventure tourism should include six major components namely activity, motivation, risk, environment, experience and performance. This is aligned with the definition from the Adventure Travel Trade Association (ATTA) which, adventure tourism as a trip must take an individual outside of his or her regular environment for more than 24 hours and include at least two of following three elements; participation in a physical activity, a visit to natural environment, and a culturally engagement experience (ATTA, 2016). To date, this definition has been accepted and used by the adventure tourism industry around the world.

Adventure tourism is a where tourists participate in a commercialized exciting activity implicating physical or mental risk and some degree of physical activity. Through the activity, adventure tourists assume to experience levels of risk, excitement and serenity, and be personally tested (Millington et al., 2001). This is the reason why risk at the heart of adventure tourism and become a central of attraction (Buckley, 2010; McKay, 2016, 2018; Mueller et al., 2016).

\subsection{Risk in Commercial Adventure Tourism Business}

There are many types of risk that business commonly faces. Risk can be a physical safety matter, a financial business risk, a risk of property loss, reputational risk and more. Risk can be as a threat in as well as an opportunity to a business. It potentially affects the business negatively or positively depending on how the businesses will manage it. The goals of risk management include the protection of assets, to minimize legal and financial liabilities, to control potential loss, properly manage growth, and to operate responsibility (Silvers, 2005). According to Clinch et al. (2017), commercial, legal, medical, physical, operational and social is a risk that important in adventure tourism. In this business, risk should be managed in three ways; safety regulation, staff, and equipment (McKay, 2014). The improper risk management in this business may lead to some issues such as injury and accidents, incompetent staff, poor safety standard, licensed and unlicensed operators, legal regulation, un-standardized operating procedures, and inadequate consumer protection.

In adventure tourism business, risk management is crucial and critical for sustainability. Risk has become a significant issue for the organization involved in all areas of adventure tourism, especially for specialist adventure operators and adventure tourism company provider. Risk in adventure tourism is about managing or optimizing it without eliminating them due to its inherent in adventure activities. Commonly, the risk level in each adventure activity is evaluated by the organizer or adventure tourism businesses to make sure the real risk is kept to minimum although the perceived risk will be high. In this situation, it is important for adventure tourism businesses to demonstrate the ability to manage risk in order to achieve a balance between safety and participant's exposure to real risk. Hence, minimising risk is essential for those organising and offering adventure trips especially for the commercial adventure tourism operators. 
The concept of risk in adventure tourism is known as adventure tourism continuum. The adventure tourism continuum is based on the idea that level of risk is involved in every activity that offers adventure tourism services (Pages et al., 2005). The level of risk can be placed along a continuum from soft adventure to hard adventures. In the soft adventure, little risk is involved and no specialized skill is required in the activities. Contradicting with hard adventure, risk level involved in this activity is high and extraordinary. Competent adventure tourism operators or instructors are required to be a guide for the participants during the activity. To participate in hard adventure activities, the participants need to be physically fit and have extreme commitment while commercial operators need specialized skills as well as experience in order to offer the services to participants due to their challenging factor.

\subsection{Commercial Adventure Tourism Business}

Adventure tourism business can be described as a business that offers exciting and challenging commercial activities in a natural outdoor setting. It can also be described as; i) adventure tourism product is the main source of income for the business, ii) the participant is a physically engaged in the activity, and iii) there is an communication in the practice of guiding or instruction between company's employee and participants throughout the course of the activity (Løseth, 2014). The business of adventure tourism has grown vastly and began extended worldwide in the past 20 years (McKay, 2013). Until today, an explosive growth in adventure tourism has occurred, with huge numbers of travellers seeking novel, challenging, and exciting adventure experience while on holiday (Williams et al., 2005). The changes of traveller's behaviour to get the more exciting experience in their holiday, has lead the surge in demand of adventure tourism products. As a response to this rapid growth in demand, a significant number of adventure tourism businesses have emerged in recent years to accommodate as well as meet the specific needs of the travellers. In this sector, the adventure tourism businesses commonly run by individual companies and predominantly by small-owner operated businesses. For instance, it has been reported in 2013 that the average size of adventure tourism companies often has not more than 44 employees (ATTA, 2016). The motivation of individual to become an adventure entrepreneur has led by a drive to share their favourites places and passions with others (World Tourism Organization, 2014).

\subsection{Injury and Incidents in Adventure Tourism}

Participation in adventure tourism is usually associated with a risk of injury or even death (Laver et al., 2017). Over 4 million injuries in adventure sports were reported between year 2000 to 2011 (Sharma et al., 2015). Recent data from Laver et al. (2017), suggested that the risk and severity of injury in global adventure tourism was unexpectedly high with approximately $70 \%$ of the total injury rate was recorded. Meanwhile in Malaysia, Zakaria et al. (2017) and Majeedkutty et al. (2017) documented that $85.7 \%$ and $83.8 \%$ respectively experienced injuries during adventure activities in their report. This high percentage of total injury rate from the recent report, proved that risk in adventure tourism is genuine. Without appropriate risk management plans, it may potentially lead to accidents and tragedies. Risks involved in adventure tourism are frequently highlighted by the media, usually after a 
reported accident of fatality. The increased in the number of reported accidents by media in the adventure tourism sector may give significant effect and harmful impact on business as well as the whole tourism industry. It would also has a negative impact on the economic, tourism industry as well as demand for adventure tourism products.

Managing risk in commercial adventure tourism operation is essential for the safety of travelers and to avoid litigation in the event of an accidents. Thus, effective management of risk in adventure tourism is pivotal for the long-operational sustainability of the sector as accidents have serious effects on its business (Clinch et al., 2017). At the same time, by having the effective risk management, it will benefit to adventure tourism businesses to grow and deliver the quality product to the customer.

\subsection{The Event Management Body of Knowledge (EMBOK) Model}

The Event Management Body of Knowledge (EMBOK) model has been identified as a potential risk management framework that can be implemented by any industry in order to organize and managing event successfully (Silvers, 2005). The International EMBOK model developed by Silvers (2004), is a conceptual framework including processes, phases, core values, and function or knowledge domains that may be customized to meet the needs of various users including governments, academic, and industry practitioners. The International EMBOK model is highly useful and was globally recognized as an effective tool for risk management (Milanović et al., 2014; Silvers, 2005, 2009). The EMBOK structure model, as shown in Figure 1 provides a three-dimensional approach to event management and suitably, risk management for individuals events. EMBOK model has been developed as a complete framework, which provides a logical and systematic approach to explain event risk management process in a complete structural and straightforward manner (Milanović et al., 2014; Silvers, 2005). The advantage of implementing EMBOK model in organizing and managing events is this framework incorporates each particular area of events that managers must be focused on, as well as provides an appropriate tool for event risk management, especially in the area of identifying potential risks (Milanovic et al., 2014). Silvers (2005) has referred risk domain to include protective obligations, opportunities, and legalities that are traditionally associated with any business. The risk domain consists of compliance management, decision management, emergency management, health and safety management, insurance management, legal management, and security management. 


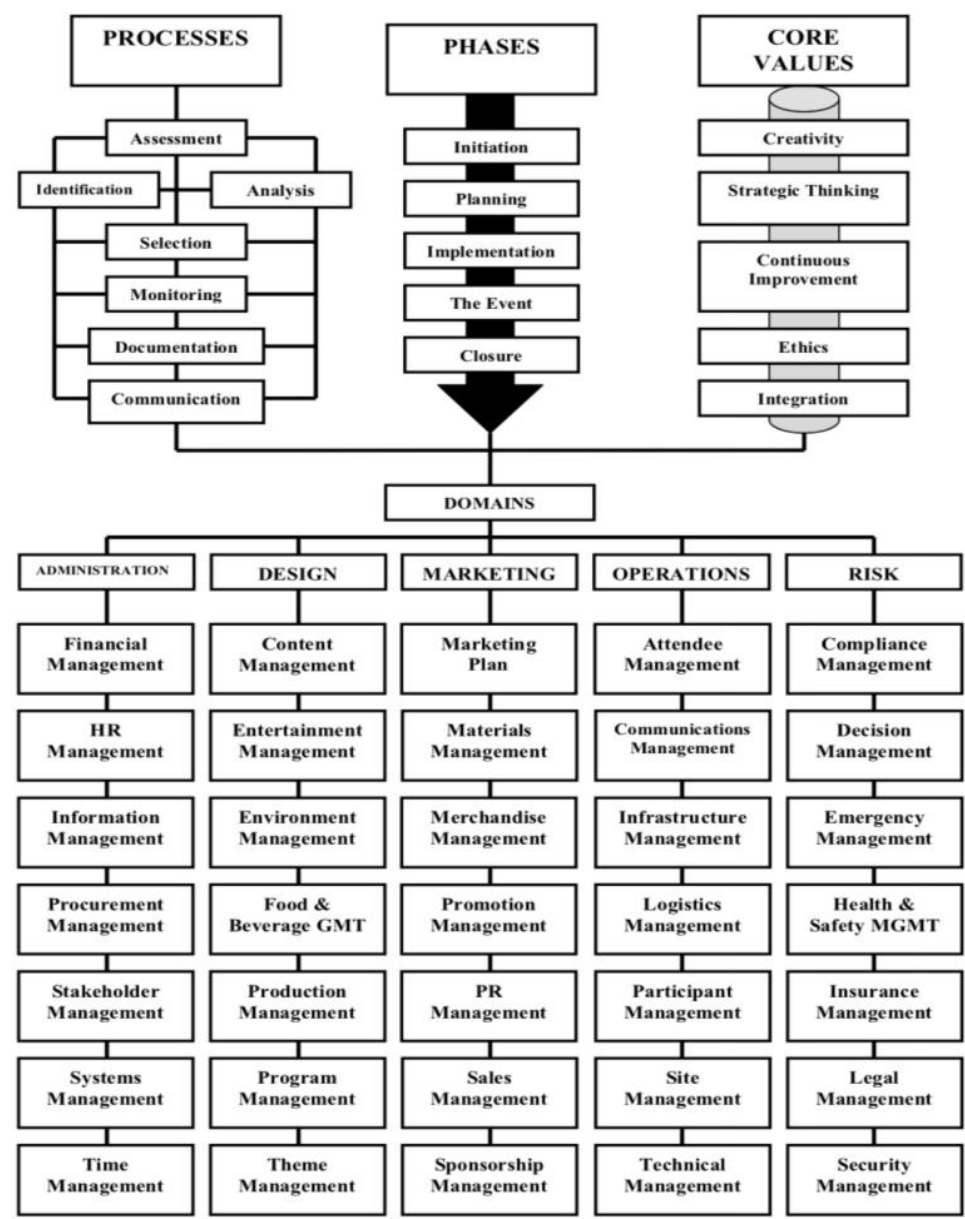

Figure 1. The structure of Event Management of Body Knowledge (EMBOK) model.

Source: Silvers (2009).

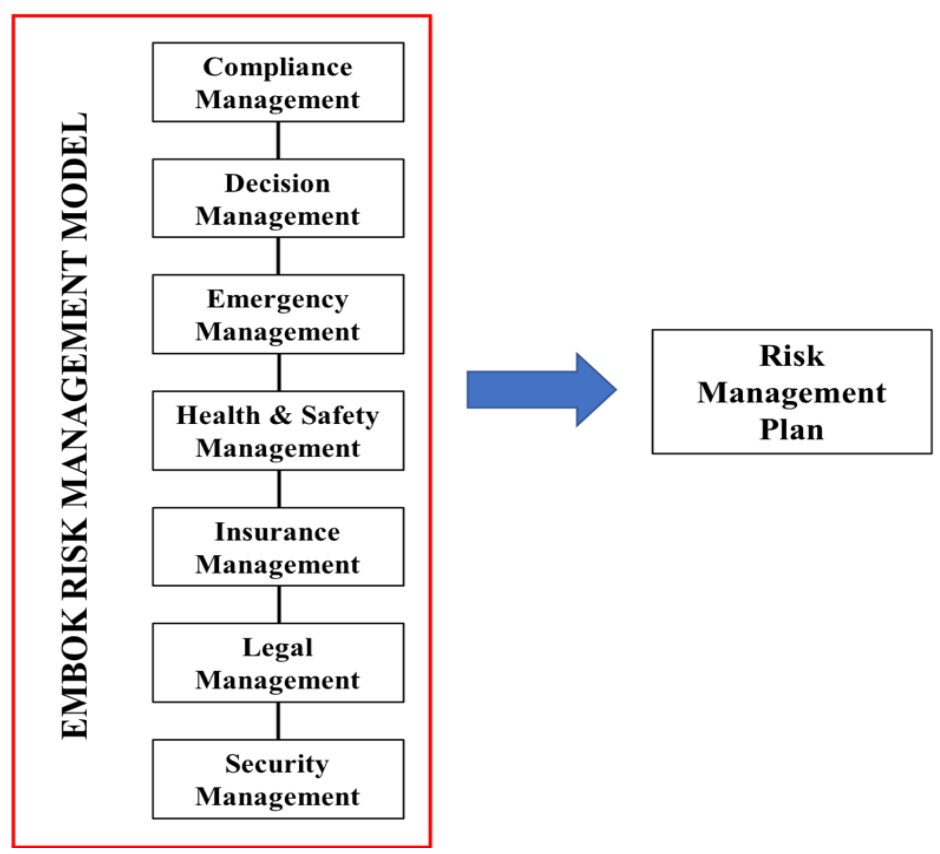

Figure 2. The EMBOK risk management model 


\section{Methodology}

Qualitative research methods have been recognized as necessary to totally grasp adventure tourism experience and significant as untapped opportunity to describe the leisure activities (Clinch et al., 2017; Løseth, 2018). Case study was chosen as a method to conduct this study due to the exploratory nature of this study (Yin, 2014). The case study has been universally used in business research due to the contribution of knowledge to researchers with related phenomena in a real-life context, where frequently it would be otherwise difficult to grasp its dimensions (Runfola et al., 2013).

Data for this study were obtained from two independent case studies. All data were collected through multiple sources which include participant observations, interviews as well as document analysis. Two local adventure operators were chosen as a case study to illustrate on how local adventure businesses manage the risks that occur in adventure tourism businesses by different conditions. These two operators were selected based on their primary activity business which mainly focus on the adventure activities. Besides the primary activity, the operators also were selected based on their business size, location, and the durations of their involvement in the adventure tourism business (Table 1).

In order to develop a level of detailed understanding of study site, participants, operational process and current situation, participant observations were conducted within December 2018 to March 2019. Participations in some of adventure activities offered by the operators, were arranged accordingly to owner and manager convenient time. During each activity, the participants were aware for the main role of researcher in this stance is to collect data. Through the involvement and direct engagement with the adventure activities, it will lead to the ability of understanding the context in which the experience of the participants occurs.

Table 1. Description of the two cases and the data material gathered from each case

\begin{tabular}{|c|c|c|c|}
\hline Business / Case & $\begin{array}{l}\text { Size / Duration } \\
\text { Involvement }\end{array}$ & Location & Data Collection Description \\
\hline $\begin{array}{l}\text { Company A } \\
\text { Rope swing, zipline, } \\
\text { hiking, waterfall } \\
\text { trekking }\end{array}$ & $\begin{array}{c}\text { > } 3 \text { Employees } \\
\text { / } \\
\text { Since } 2010\end{array}$ & $\begin{array}{c}\text { Kuala Kubu } \\
\text { Baru, Selangor }\end{array}$ & $\begin{array}{l}\text { Interview with the owner of the } \\
\text { business. Participate in one of the } \\
\text { activities and observe on how the } \\
\text { activity is being conducted. }\end{array}$ \\
\hline $\begin{array}{l}\text { Company } B \\
\text { White water rafting, } \\
\text { waterfall abseiling, } \\
\text { caving, jungle } \\
\text { trekking, tubing }\end{array}$ & $\begin{array}{c}>40 \text { Employees } \\
\text { / } \\
\text { Since } 1995\end{array}$ & Kampar, Perak & $\begin{array}{l}\text { Interview with the manager of the } \\
\text { business. Participate in three activities } \\
\text { and observe on how the activity is } \\
\text { being conducted. Having informal } \\
\text { conversation with river guide and } \\
\text { river safety. }\end{array}$ \\
\hline
\end{tabular}

Semi-structured interviews were carried out with adventure tourism operator owners and manager at the end of each activity. These interview sessions took place at activity site, and 
lasted on average one hour for each interview. The interview questions were adapted from the EMBOK risk domain and focusing on management areas that related to adventure tourism context. With the informant permission, interviews were voice recorded to ensure accuracy. Other than formal interviews, field notes from informal conversation with the informants were also used to provide additional data. All noted documents were transcribed and analysis was carried out through the identification of prominent themes running through the responses. $\mathrm{N}$-vivo (version 12) was used as a analysis tool to organise and analyse contents from all sources. To keep the secrecy of the interviewees, alphabetic initials were used in this paper when making citation to their statements.

\section{Findings \& Discussion}

\subsection{Safety Risks in Adventure Tourism Businesses}

Understanding how operators manage risk is crucial to the development of adventure tourism. However, ability of the operators to manage risks depends on their understanding of the risks or injury that normally occur during the activities. Both informants mentioned that slip, fall, small cut and ankle sprain is a common actual injury experienced by tourists. Statements from both informants were also supported by the findings of the researchers through observation in which at least six out of $20(30 \%)$ tourists experienced minor injuries such as slip and small cut during the activity. These statements and findings are consistent with previous findings and reports, which slip, trip, fall and ankles sprain are the major causes of injury among adventure travelers (Bentley et al., 2010).

In addition, this study exposed that equipment was presented as a one factor to create the situations which lead to increase casualty and injury. According to Informant A, most of injury was cause from the failure of equipment.

"Yes, for zipline.... Sometimes the brake (pulley) stuck and it stop immediately (at the middle of line). The participant had some cut. There is another incident when the zipline was not stop exactly at the stopper. So, the participant falls down. Luckily there are no serious injuries happen. Just slip and sprained" (Informant A)

Previous study revealed that $16 \%$ of incidents were linked to equipment failure (Salla, 2014). Without regular inspection and maintenance, potential of equipment failed working is high.

"Equipment condition is important to our business. We will make sure the equipment is safe and in the good condition to avoid any circumstances. This will help to reduce the injury risk” (Informant B).

Functional and safe equipment is vital for adventure tourism commercial activities. Hence, operators should be responsible to check their equipment to guaranteed safety of the tourists and avoid them from any hurts. Effective and functional equipment also important to ensure the tourists satisfaction and excitement.

\subsection{Compliance and Qualification}

Qualification and standards used in adventure tourism business is essential to control 
commercial environments with high frequency participation, professional duty of care, commercial pressure and competition. This study shows that guide safety and risk management was derived and depends through the entrepreneur's own initiatives.

"No specific guideline. However, we have referred to one guideline. It's called HIRAC (general risk management plan). It's had rules and regulations checklists." (Informant A)

"There are no specific guidelines form government. Our guideline was created by our own. We use a pyramid model. However, this model only for reduce the injury rate while activity conducted to avoid the major or bad incident happen." (Informant B)

Both informants mentioned that there are no specific regulations and standard guideline imposed by the any governing bodies of agencies for adventure tourism businesses to comply to. Most of the local adventure tourism operators develop their own risk management plans based on their experiences in this industry. Hence, without any specific regulation and standard guideline, all adventure tourism operators in Malaysia should have the responsibility to manage and create their own risk management plan to ensure they can provide safety experience to the clients.

Although previous literature argued that risk management is an adventure tourism operator responsibility (Buckley, 2010), a better level of safety standard guideline should be imposed by the governing bodies or related agencies. By having a standard regulation and guideline an authority in the form of licensing, qualifications and insurance can be applied (Clinch et al., 2017). This study disclosed, currently there are no requirement for specific license and qualification that local operators should apply to run this adventure tourism business. The consequence, there are no authorize body in Malaysia accountable to monitor and perform a routine safety audit procedure including the equipment specification and qualified guides. Qualification guides is important for the success of adventure tourism operator due to generally deal with inexpert and unskilled tourists. This is in line with Clinch et al. (2017) who states that qualifications will assist the enhancement of the safety and the overall experience will contribute to the any decision making related to the risk management procedure. This highlights the reason why routine safety audits should be enforced by authorized bodies. Apart from safety issues, it will ensure the operators running this business appropriately and lead to the development of this industry in this country.

"No specific body are involved and ask for the safety audit in this industry. We should take this responsibility by our own initiates..... Based on the experiences in this industry, most our guide had at least first aid certification and our guide river should have IRF certification. That's why we prefer to have permanent guide and not the freelance guide." (Informant B)

The outcomes from this setting, obviously will give the negative impact to industry. The lack of control and monitoring from governing bodies will lead to growth and unrestricted of unqualified and irresponsible operators in this industry. This also has become one of the reasons why there are certain operators still ignoring the right procedures of risk management and lead to jeopardized client's safety. 


\subsection{Legal and Insurance}

To provide clients with standard of care, a compulsory legal guidelines are required for adventure tourism businesses. By having the legal requirement, adventure tourism business will be able to face the legal consequence if there are any incident happen. However, this legal requirement can be only implemented if there have specific regulation and standard guidelines by governing bodies in this industry. Legal requirement form part of minimum standard of safety adherence for adventure tourism businesses. A sequence of laws will deliver a right approach to outdoor settings pertaining to this industry. For example, activity operation guidelines, code of practices, health and safety procedure, employee training, and equipment standard.

An insurance policy is very significant to the clients nor the businesses. Through this series of laws, policy insurance for adventure tourism can be provided. This is because, the insurance policy contains a plan of action which has been agreed formally as the basis for deciding or action. Until today, insurance that relates to adventure tourism in Malaysia are still limited due to no legal requirement. Therefore, most of operators in Malaysia applies the concept of "at your own risk". Clients are required to sign and fill up the indemnity form in order to release of liability from businesses before proceed with the activity.

"Once you sign the indemnity form, automatically all insurance cover is void. You do under your requests" (Informant A)

However, the advantage of insurance policy not only important to the clients. Businesses need the insurance policy to transfer management to the third-party liability insurance (Zakaria et al., 2016). This certainly will help the management from the huge losses due forced to pay compensations causing from non-term negligence.

\section{Conclusion}

Result from the both case study illustrated that local adventure tourism businesses have no specific guidelines and risk management models that they should adhere to. This study also identified that adventure tourism industry in Malaysia totally require an appropriate and positive risk management practices.

Through the primary research, this study recognized that good risk management practices model should have all the aspect compliance, decision, health and safety, insurance and legal aspects. All the aspects that has been discussed and acknowledge important by adventure tourism operator is stated on the risk domain of EMBOK model. Thus, this study will advise to apply and implement of the EMBOK model as part of Malaysian adventure tourism businesses risk management responsibilities.

In addition, findings from this study also demonstrated that no specific regulations imposed by the government for adventure tourism businesses to comply to. In order to have the good risk management practices, support and action from government are required. Regulation and standard safety guideline should be prepared and execute to ensure the licenses, safety audits, 
permits as well as insurance policies can be applied. By having a good risk management practices will help drive the country's economic performance and indirectly gives a strong impact on the country's adventure tourism industry.

\section{References}

ATTA, Adventure Travel Trade Association. (2013). The George Washington University, Xola Consulting. (2010). Adventure tourism market study.

ATTA, Adventure Travel Trade Association. (2016). Adventure Tourism Development Index: An Adventure Travel Scorecard Retrieved from https://www.adventuretravel.biz/

Bentley, Tim A, Cater, Carl, \& Page, Stephen J. (2010). Adventure and ecotourism safety in Queensland: Operator experiences and practice. Tourism Management, 31(5), 563-571. https://doi.org/10.1016/j.tourman.2009.03.006

Bentley, Tim A, Page, Stephen J, \& Laird, IS. (2001). Accidents in the New Zealand adventure tourism industry. Safety Science, 38(1), 31-48. https://doi.org/10.1016/S0925-7535(00)00053-9

Buckley R. (2010). Adventure tourism management (First ed). Elsevier Ltd. https://doi.org/10.4324/9781856178358

Buckley R. (2014). Chinese model for mass adventure tourism. Tourism management, 44(2014), 5-13. https://doi.org/10.1016/j.tourman.2014.01.021

Clinch, Hannah, \& Filimonau, Viachaslau. (2017). Instructors' perspectives on risk management within adventure tourism. Tourism Planning \& Development, 14(2), 220-239. https://doi.org/10.1080/21568316.2016.1204360

Doshi, Yash, \& Das, Debojyoti. (2018). Adventure Tourism Market - Global Opportunity Analysis and Industry Forecast 2017-2023. Retrieved from https://www.alliedmarketresearch.com/adventure-tourism-market

Ibrahim, Mohd Zulhalmi, Mapjabil, Jabil, Kumalah, Mohd Jirey, Wan Mohd Amin, Wan Abd Aziz, Rosmiza, M.Z., \& Marzuki, Mazdi. (2016). Potentials and prospects of sport tourism in Malaysia: A theoretical perspective. World Applied Sciences Journal, 34(12), 1678-1684.

Isa, Siti Suriawati, Hasbullah, Rashidi, \& Nasir, Mohd Nizam Mohd. (2015). Adventure and Ecotourism in Malaysia. Adventure And Ecotourism In Malaysia, 1.

Laver, Lior, Pengas, Ioannis P, \& Mei-Dan, Omer. (2017). Injuries in extreme sports. Journal of orthopaedic surgery and research, 12(1), 59. https://doi.org/10.1186/s13018-017-0560-9

Løseth, Kristin. (2018). Knowledge development in adventure tourism businesses-the influence of serious leisure. Annals of Leisure Research, 21(5), 575-591. https://doi.org/10.1080/11745398.2017.1406808

Majeedkutty, Nizar A, \& Khairulanuar, Nor AB. (2017). Prevalence, patterns, and correlates 
of equestrian injuries in Malaysia: A cross-sectional study. Journal of family \& community medicine, 24(1), 18. https://doi.org/10.4103/2230-8229.197177

Mapjabil, Jabil, Marzuki, Mazdi, Kumalah, Mohd Jirey, Tangavello, Logeswaran, \& Abidin, Mohammad Kadir Zainal. (2017). Sport as a tourism attraction in Malaysia: Potential and prospects. Geografia-Malaysian Journal of Society and Space, 11(12).

McKay, Tracey. (2013). Adventure tourism: opportunities and management challenges for SADC destinations. Acta academica, 45(3), 30-62.

McKay, Tracey. (2016). The geography of the South African adventure tourism industry. African Journal of Hospitality, Tourism and Leisure, 5(3), 1-21.

McKay, Tracey. (2018). An analysis of the South African adventure tourism industry. An International Journal of Tourism and Hospitality Research, 29(4), 529-539. https://doi.org/10.1080/13032917.2018.1455151

McKay, Tracey. (2014). Locating South Africa within the global adventure tourism industry: the case of bungee jumping. Bulletin of Geography. Socio-economic Series, 24(24), 161-176. https://doi.org/10.2478/bog-2014-0020

Milanović, Nemanja, \& Ješić, Mia. (2014). Event Risk Management-EMBOK Model Approach. Serbian Project Management Journal, 60.

Millington, K., Locke, T. and Locke, A. (2001). Occasional studies: adventure travel. Travel and Tourism Analyst, 4, 65-97

Mueller, F., F., \& Pell, S., J. (2016). Technology meets adventure: Learnings from an earthquake-interrupted Mt. Everest expedition. In Proceedings of the 2016 ACM International Joint Conference on Pervasive and Ubiquitous Computing ACM, Heidelberg, Germany: 817- 828. https://doi.org/10.1145/2971648.2971683

Naidoo, P, Ramseook-Munhurrun, P, Seebaluck, NV, \& Janvier, S. (2015). Investigating the motivation of baby boomers for adventure tourism. Procedia-Social and Behavioral Sciences, 175, 244-251. https://doi.org/10.1016/j.sbspro.2015.01.1197

Peacock, Suzanne, Brymer, Eric, Davids, Keith, \& Dillon, Michelle. (2017). An ecological dynamics perspective on adventure tourism. Tourism Review International, 21(3), 307-316. https://doi.org/10.3727/154427217X15022104437756

Runfola, Andrea, Rosati, Massimo, \& Guercini, Simone. (2013). New business models in online hotel distribution: emerging private sales versus leading IDS. Service Business, 7(2), 183-205. https://doi.org/10.1007/s11628-012-0150-1

Salla, Purvi. (2014). New Zealand as a safe adventure destination is it a reality? (Master's thesis, Auckland University of Technology). Retrieved from https://pdfs.semanticscholar.org/fdef/fe6f14f9a33ec5b7d55b0c71fd002b29cc83.pdf 
Senthilkumaran, Piramanayagam, \& Pratim, Seal Partho. (2017). Intervention strategies to mitigate risk in adventure tourism: A Haddon matrix perspective. Disaster Advances, 10(11), 21-25.

Sharma, Vinay K, Rango, Juan, Connaughton, Alexander J, Lombardo, Daniel J, \& Sabesan, Vani J. (2015). The current state of head and neck injuries in extreme sports. Orthopaedic journal of sports medicine, 3(1). https://doi.org/10.1177/2325967114564358

Silvers, Julia Rutherford. (2004). Updated EMBOK Structure as a Risk Management Framework for Events. Retrieved from http://www.juliasilvers.com/embok/E MBOK_structure_update.htm

Silvers, Julia Rutherford. (2005). The potential of the EMBOK as a risk management framework for events. Las Vegas. [Online] Available: http://www.juliasilvers.com/embok. html [accessed 2008].

Silvers, Julia Rutherford. (2009). Risk management for meetings and events: Routledge. https://doi.org/10.1016/B978-0-7506-8057-8.50009-2

Page, Stephen J, Tim A. Bentley, Linda Walker. (2005). Scoping the nature and extent of adventure tourism operations in Scotland: how safe are they?. Tourism Management 26(2005), 381-397. https://doi.org/10.1016/j.tourman.2003.11.018

Sung, Heidi H, Morrison, Alastair M, \& O'Leary, Joseph T. (1996). Definition of adventure travel: Conceptual framework for empirical application from the providers' perspective. Asia Pacific journal of tourism research, 1(2), 47-67. https://doi.org/10.1080/10941669708721975

Swarbrooke, John, Beard, Colin, Leckie, Suzanne, \& Pomfret, Gill. (2003). Adventure tourism: The new frontier: Routledge. https://doi.org/10.1016/B978-0-7506-5186-8.50017-9

William Pauls, Soutar Geoffrey. (2005). Close to the "edge": Critical issues for adventure tourism operators. Asia Pacific Journal of Tourism Research 10(3), 247-261. https://doi.org/10.1080/10941660500309614

World Tourism Organization. (2014). AM Reports, Volume nine - Global Report on Adventure Tourism, UNWTO, Madrid. https://doi.org/10.18111/9789284416622

Yin, Robert K. (2014). Case Study Research: Design and Methods (Fifth ed.): SAGE Publications, Inc.

Yusof, Aminuddin, Shah, P, Omar-Fauzee, Mohd Sofian, \& Hakim, MN. (2008). Sport tourist motives: Implications for market segmentation and tourist destination selection. The International Journal of Knowledge, Culture and Change Management, 7(12), 39-45. https://doi.org/10.18848/1447-9524/CGP/v07i12/50465

Zakaria, Jaffry, Yasim, Mazuki Mohd, Taff, Md Amin Md, Dasril, Benderi, \& Mustafa, Mirza Azny. (2017). White water kayaking risk: Malaysian perspective. Open Access Library Journal, 4(03), 1. https://doi.org/10.4236/oalib.1103168 


\section{Copyright}

Copyright for this article is retained by the author(s), with first publication rights granted to the journal.

This is an open-access article distributed under the terms and conditions of the Creative Commons Attribution license (http://creativecommons.org/licenses/by/4.0/). 